\title{
Hasil Validasi Modul 6M Berbasis Project Based Learning untuk Peserta Didik SMA
}

\author{
Fitri Rahmawati ${ }^{1}$, Hamdani $^{2}$ \\ Dosen Program Studi Pendidikan Biologi, FKIP, Universitas Cordova ${ }^{1,2}$ \\ Email: 10fitri.rahma@gmail.com
}

\begin{abstract}
Abstrak
Penelitian yang telah dilaksanakan bertujuan untuk mengembangkan modul 6M berbasis project based learning untuk peserta didik SMA di Kabupaten Sumbawa Barat. Penelitian pengembangan menggunakan model ADDIE dengan melalui tahapan yaitu proses validasi ahli (konstruk dan isi) oleh dua validator ahli sehingga hasil validasi pengembangan Modul 6M dapat diterapkan dalam proses pembelajaran. Hasil penelitian berupa dua kali validasi ahli dari dua orang validator ahli. Hasil validasi ahli pertama adalah rerata skor “68,75\%" dengan kriteria Cukup dan rerata skor untuk kriteria penilaian Valid dengan skor 2,75. Adapun hasil validasi ahli kedua adalah rerata skor "87,5\%" dengan kriteria Sangat Baik dan rerata skor untuk kriteria penilaian Sangat Valid dengan skor 3,5. Hasil validasi menunjukkan bahwa Modul 6M berbasis project based learning sehingga dapat diterapkan dalam proses pembelajaran peserta didik SMA kelas X.
\end{abstract}

Kata kunci: Validasi, Modul 6M, PjBL, Peserta Didik, SMA.

\section{PENDAHULUAN}

Kegiatan pengajaran atau proses pembelajaran harus bisa mencapai tujuan pembelajaran yang diharapkan, hal tersebut tentunya harus sesuai dengan kebutuhan dan kemampuan peserta didik (Saprin, 2016 ${ }^{[1]}$. Pendidikan harus mampu mencetak individuindividu yang mempunyai pengetahuan tinggi, daya kompetitif, kreativitas, dan sikap budi pekerti agar kualitas sumber daya manusia semakin meningkat. Guru perlu menciptakan lingkungan yang kondusif bagi para peserta didik dengan menggunakan model pembelajaran yang tepat. Dengan menggunakan model pembelajaran yang tepat, peserta didik tidak hanya dituntut untuk mendengar dan menghafal materi yang diberikan oleh guru, tetapi peserta didik juga aktif dalam mencari materi yang akan dipelajarinya. Peserta didik akan terdorong untuk berpikir kreatif dan bertanggungjawab atas apa yang akan mereka pelajari sehingga peserta didik dapat memecahkan masalah yang dihadapi baik yang berkaitan dengan sekolah maupun permasalahan yang terjadi dalam kehidupan bermasyarakat.

Hasil observasi di sekolah diperoleh informasi bahwa sejauh ini belum pernah dilakukan proses pengembangan bahan ajar berupa modul dalam pembelajaran, khususnya materi perubahan lingkungan kelas X SMA karena guru dan siswa masih menggunakan buku teks pelajaran yang telah ada dan diperjual belikan di toko-toko buku. Modul $6 \mathrm{M}$ dikembangkan berdasarkan kebutuhan peserta didik sebagai suatu upaya mencapai tujuan pembelajaran yang lebih baik

Model pembelajaran yang tepat yang dapat dipadukan dengan bahan ajar berupa Modul 6M yaitu project based learning (PjBL) yaitu merupakan model pembelajaran yang sesuai untuk mengembangkan keterampilan intelektual dan keterampilan keterampilan lainnya, seperti membuat perencanaan project, pelaksanaan, dan pelaporan hasil project dalam bentuk presentasi serta menghasilkan karya atau produk. Menurut Kosasih (2014) [2] menyatakan bahwa model pembelajaran project based learning adalah model pembelajaran yang menggunakan proyek atau kegiatan sebagai tujuannya. Pembelajaran difokuskan pada pemecahan masalah yang menjadi tujuan utama dari proses belajar sehingga dapat memberikan pembelajaran yang lebih bermakna karena dalam belajar tidak hanya mengerti apa yang dipelajari tetapi membuat peserta didik menjadi tahu apa manfaat dari pembelajaran tersebut untuk lingkungan sekitarnya. PjBL terdiri dari beberapa tahapan diantaranya adalah (1)penyajian informasi, (2) penentuan pertanyaan mendasar, (3) mengorganisasi kelompok, (4) menyusun perencanaan proyek, 
(5) Menyusun jadwal, (6) monitoring pelaksanaan proyek, (7) penilaian dan evaluasi. Pembelajaran berbasis proyek memberi peluang menjangkau pelajaran yang lebih luas ke dalam kelas. Hal itu dapat dilakukan dengan melibatkan anak-anak dari latar belakang budaya yang berbeda karena Branch, R.M (2009) [4] menyatakan bahwa model pengembangan ADDIE terdiri dari lima tahapan utama dengan rincian kegiatan berupa : (1) Analisis

Perancangan.

Pengembangan.

Penerapan, dan (5) Penilaian. Penjelasan untuk setiap tahap sebagai berikut: (1) Pendefinisian (Define), yaitu mendefinisikan serta menetapkan apa saja syarat dalam pembelajaran. (2) Perancangan (Design) dengan merancang perangkat pembelajaran seperti silabus, RPP, dan modul $6 \mathrm{M}$ berbasis project based learning serta merancang instrumen penelitian yang meliputi soal pretes dan post-test, angket validasi konstruk dan isi modul 6M dan angket validasi keterbacaan modul $6 \mathrm{M}$ berbasis project based learning. (3) Pengembangan (Develop) sebagai tahapan untuk menghasilkan produk pengembangan modul melalui penilaian ahli (dua validator) yang disertai dengan revisi serta uji keterbacaan modul $6 \mathrm{M}$ oleh peserta didik kelas X SMA. (4) penerapan (implementation) dengan melakukan uji coba terbatas pada uji keterbacaan peserta didik, dan terakhir (5) Evaluasi (evaluation) yaitu penilaian perangkat pembelajaran dan instrumen penelitian.

Modul 6M berbasis project based learning yang dikembangkan pada penelitian ini mengacu pada hasil pengembangan modul yang dilakukan oleh (Vendiktama, 2018) ${ }^{[5]}$. Model pembelajaran yang dipilih bertujuan untuk membantu dan melatih peserta didik dalam melakukan kegiatan proyek. Petunjuk praktikum yang dikembangkan melalui proses pengembangan yang mengacu pada tahapan pengembangan ADDIE yaitu tahapan validasi ahli (konstruk dan isi) oleh dua validator dan uji keterbacaan oleh peserta didik agar hasil pengembangan dapat diterapkan lebih lanjut dalam proses pembelajaran IPA Kelas $\mathrm{X}$ SMA. anak-anak dapat memilih topik-topik yang dihubungkan dengan pengalaman pengalaman mereka sendiri, dengan berbagai cara belajar sesuai dengan karakter individu atau budaya $(\text { Mahanal, 2009) })^{[3]}$.

Pengembangkan Modul 6M berbasis project based learning untuk peserta didik SMA di Kabupaten Sumbawa Barat perlu dilakukan untuk mencapai proses dan hasil pembelajaran yang lebih baik dan berkualitas.

\section{METODE PENELITIAN}

Penelitian yang dilakukan merupakan penelitian pengembangan yang menggunakan model pengembangan ADDIE menurut Branch, R.M (2009). Tahapan proses pengembangan tertera pada Gambar 1 .

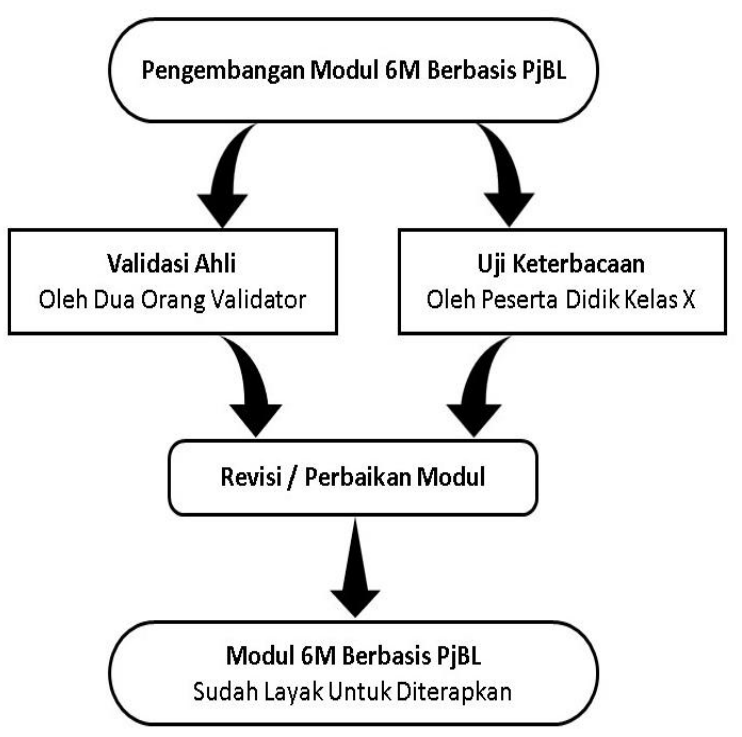

Gambar 1. Tahapan Pengembangan ADDIE

Validator ahli modul
berbasisproject based learning
telah
dilakukan oleh Dosen FKIP Program Studi
Pendidikan Biologi Universitas Cordova
(Hilda Ernani, S.Pd., M. Pd dan Sahratullah,
S.Pd., M.Pd.). Hasil validasi ahli oleh dua
validator kemudian akan dianalisis
menggunakan teknik analisis rerata skor
dengan kriteria kevalidan berdasarkan rerata
skor oleh Vendiktama, dkk (2018) serta
kriteria persentase hasil validasi dari


Fajarianingtyas dan Hidayat (2019) ${ }^{[6]}$ seperti tertera pada Tabel 1 dan Tabel 2.

Tabel 1. Kriteria kevalidan Modul 6M berbasis project based learning (PjBL)

\begin{tabular}{cc}
\hline Rerata skor & Kriteria penilaian \\
\hline $3,50-4,00$ & Sangat valid \\
\hline $2,50-3,49$ & Valid \\
\hline $1,50-2,49$ & Tidak valid \\
\hline $1,00-1,49$ & Sangat tidak valid \\
Persentase (\%) $=\frac{\text { jumlah (jawaban } \times \text { bobot setiap pilihan) }}{\mathrm{N} \times \text { bobot tertinggi }} \times 100 \%$
\end{tabular}

Tabel 2. Kriteria hasil validasi konstruk dan isi modul 6M Berbasis project based learning ( $\mathrm{PjBL})$

\begin{tabular}{ccc}
\hline $\begin{array}{c}\text { Tingkat } \\
\text { pencapaian }(\%)\end{array}$ & Kriteria & Keterangan \\
\hline$>80$ & Sangat baik & Tidak perlu direvisi \\
\hline $70-79$ & Baik & Tidak perlu direvisi \\
\hline $60-69$ & Cukup & Direvisi \\
\hline $50-59$ & Kurang & Direvisi \\
\hline$<50$ & Sangat kurang & Direvisi \\
\hline
\end{tabular}

\section{HASIL PENELITIAN DAN PEMBAHASAN}

Proses penelitian yang telah dilakukan menghasilkan produk berupa Modul 6M berbasis project based learning $(\mathrm{PjBL})$ untuk peserta didik SMA kelas X. Hasil validasi dua orang validator ahli untuk konstruk dan isi modul 6M berbasis project based lerning dapat dilihat pada Tabel 3. Saran, masukan, dan komentar dari kedua validator adalah perlu ditambahkan peta konsep pada modul, tambahkan Link atau website yang dapat dengan mudah diakses oleh peserta didik terkait topik pada modul serta perbanyak gambar ilustrasi. Serta perbaiki tampilan peta konsep agar lebih menari.

Tabel 3. Hasil validasi ahli pertama modul $6 \mathrm{M}$ berbasis project based learning $(\mathrm{PjBL})$

\begin{tabular}{|c|c|c|}
\hline \multirow[t]{2}{*}{ Aspek yang dinilai } & \multicolumn{2}{|c|}{ Skor } \\
\hline & Validator I & Validator II \\
\hline $\begin{array}{l}\text { Kejelasan gambar yang } \\
\text { ditampilkan }\end{array}$ & 3 & 4 \\
\hline Warna pada bagian cover & 3 & 3 \\
\hline $\begin{array}{l}\text { Ukuran gambar yang } \\
\text { ditampilkan }\end{array}$ & 2 & 2 \\
\hline $\begin{array}{l}\text { Makna gambar yang } \\
\text { ditampilkan }\end{array}$ & 3 & 3 \\
\hline \multicolumn{3}{|l|}{$\begin{array}{l}\text { Petunjuk pelaksanaan } \\
\text { praktikum }\end{array}$} \\
\hline Penjabaran & 3 & 3 \\
\hline
\end{tabular}

\begin{tabular}{|c|c|c|}
\hline Tahapan cara kerja praktikum & 2 & 2 \\
\hline $\begin{array}{l}\text { Kalimat pada petunjuk } \\
\text { praktikum }\end{array}$ & 3 & 3 \\
\hline $\begin{array}{l}\text { Redaksi kalimat pada } \\
\text { petunjuk praktikum }\end{array}$ & 3 & 2 \\
\hline $\begin{array}{l}\text { Makna kalimat pada petunjuk } \\
\text { praktikum }\end{array}$ & 3 & 3 \\
\hline Rerata skor seluruh aspek & 2 & 3 \\
\hline Persentase Skor & $67,5 \%$ & $70 \%$ \\
\hline Rata-rata Skor & \multicolumn{2}{|c|}{$68,75 \%$} \\
\hline Kriteria & \multicolumn{2}{|c|}{ Cukup } \\
\hline
\end{tabular}

Hasil validasi ahli pertama terhadap pengembangan Modul 6M berbasis project based learning menunjukkan hasil kevalidan modul 6M dengan hasil rerata skor yaitu $\mathbf{2 , 7 5}$ dengan kriteria "valid" hasil validasi ahli oleh dua validator dengan kriteria "cukup" dengan nilai rerata skor $\mathbf{6 8 , 7 5 \%}$. Pencapaian hasil tersebut disebabkan karena adanya kegiatan evaluasi yang dilakukan sesuai dengan tahapan kelima dari pengembangan modul $6 \mathrm{M}$ berbasisproject based learning yang mengacu pada model pengembangan ADDIE oleh Branch (2009). Tahapan validasi pengembangan modul $6 \mathrm{M}$ sudah sampai pada tahapan evaluasi yang telah dilakukan yaitu proses validasi ahli kedua, dengan hasil sebagai berikut.

Tabel 4. Hasil validasi ahli pertama modul $6 \mathrm{M}$ berbasis project based learning (PjBL)

\begin{tabular}{|c|c|c|}
\hline \multirow[t]{2}{*}{ Aspek yang dinilai } & \multicolumn{2}{|c|}{ Skor } \\
\hline & Validator I & Validator II \\
\hline $\begin{array}{l}\text { Kejelasan gambar yang } \\
\text { ditampilkan }\end{array}$ & 4 & 4 \\
\hline Warna pada bagian cover & 3 & 3 \\
\hline $\begin{array}{l}\text { Ukuran gambar yang } \\
\text { ditampilkan }\end{array}$ & 4 & 3 \\
\hline $\begin{array}{l}\text { Makna gambar yang } \\
\text { ditampilkan }\end{array}$ & 3 & 3 \\
\hline \multicolumn{3}{|l|}{$\begin{array}{l}\text { Petunjuk pelaksanaan } \\
\text { praktikum }\end{array}$} \\
\hline $\begin{array}{l}\text { Penjabaran } \\
\text { referensi/literatur/teori }\end{array}$ & 3 & 3 \\
\hline Tahapan cara kerja praktikum & 4 & 4 \\
\hline $\begin{array}{l}\text { Kalimat pada petunjuk } \\
\text { praktikum }\end{array}$ & 3 & 3 \\
\hline $\begin{array}{l}\text { Redaksi kalimat pada } \\
\text { petunjuk praktikum }\end{array}$ & 4 & 4 \\
\hline $\begin{array}{l}\text { Makna kalimat pada petunjuk } \\
\text { praktikum }\end{array}$ & 3 & 4 \\
\hline Rerata skor seluruh aspek & 4 & 4 \\
\hline Persentase Skor & $87,5 \%$ & $87,5 \%$ \\
\hline Rata-rata Skor & \multicolumn{2}{|c|}{$87,5 \%$} \\
\hline Kriteria & \multicolumn{2}{|c|}{ Sangat Baik } \\
\hline
\end{tabular}


Hasil validasi ahli kedua terhadap pengembangan Modul 6M berbasis project based learning menunjukkan hasil kevalidan modul 6M dengan hasil rerata skor yaitu 3,5 dengan kriteria "sangat valid" hasil validasi ahli oleh dua validator dengan kriteria "Sangat Baik" dengan nilai rerata skor $\mathbf{8 7 , 5 \%}$. Kegiatan validasi ahli ini telah sesuai dengan kegiatan validasi yang telah dilakukan oleh Sahratullah dan Rahmawati (2020) ${ }^{[7]}$

Penelitian yang dilakukan menghasilkan produk berupa modul 6M berbasis project based learning (PjBL) yang tentunya telah disesuaikan dengan sintak pembelajaran PjBL (Mahanal (2009). Bagianbagian dari modul $6 \mathrm{M}$ berbasis project based learning (PjBL) terdiri dari bagian Sampul Depan, Tentang penulis, Kata Pengantar, Daftar isi, Glosarium, Peta konsep, Petunjuk penggunaan modul, $\mathrm{KD}$ dan Indikator pembelajaran, Kegiatan pembelajaran 1, Kegiatan pembelajaran 2, Tes formatif, Tes sikap, Checklist manifestasi perilaku peserta didik, Lembar penilaian, Umpan balik, Daftar pustaka, serta Sampul belakang. Bagianbagian dari modul $6 \mathrm{M}$ berbasis $\mathrm{PjBL}$ dapat dilihat dibawah ini:

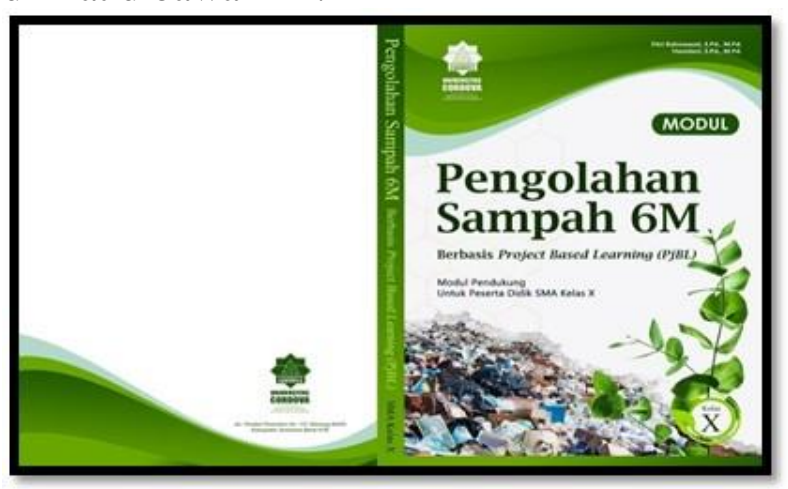

Gambar 2. Sampul depan dan belakang Modul 6M berbasis project based learning

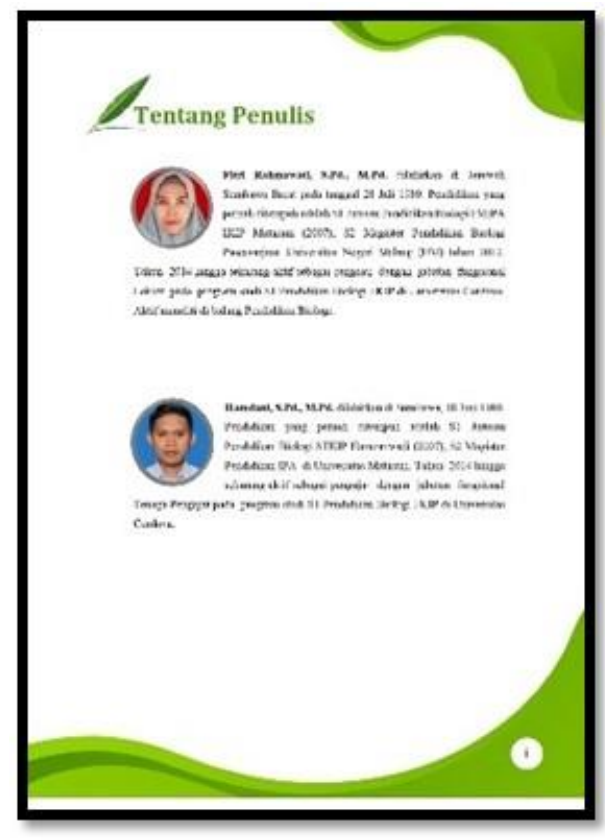

Gambar 3. Tentang Penulis
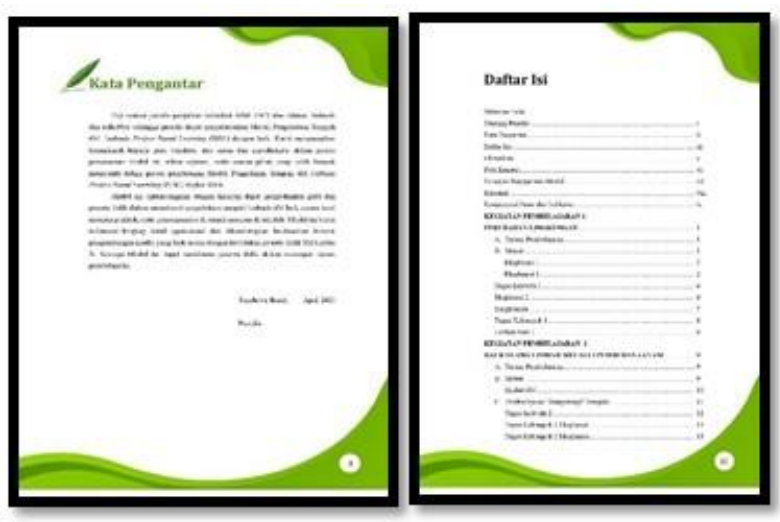

Gambar 4. Kata Pengantar dan Daftar isi

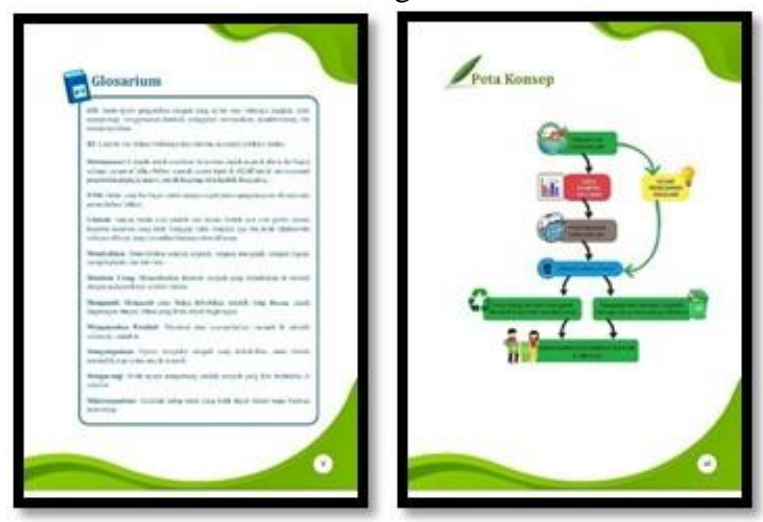

Gambar 5. Glosarium dan Peta Konsep 

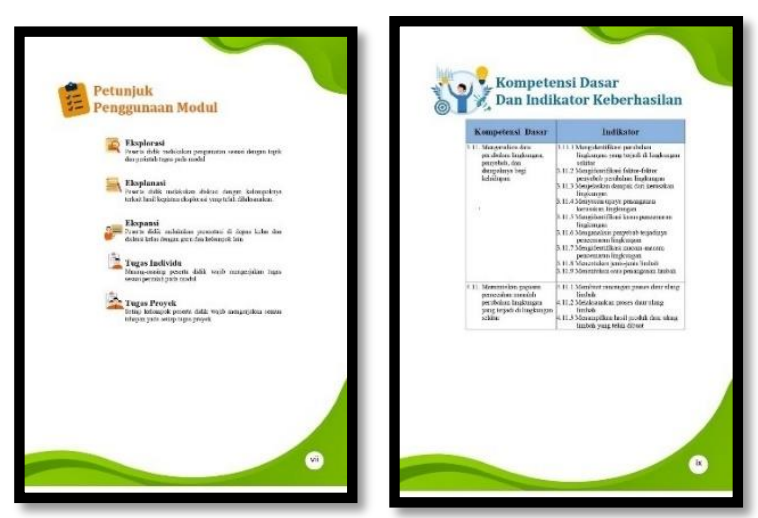

Gambar 6. Petunjuk Penggunaan Modul, Kompetensi Dasar dan Indikator
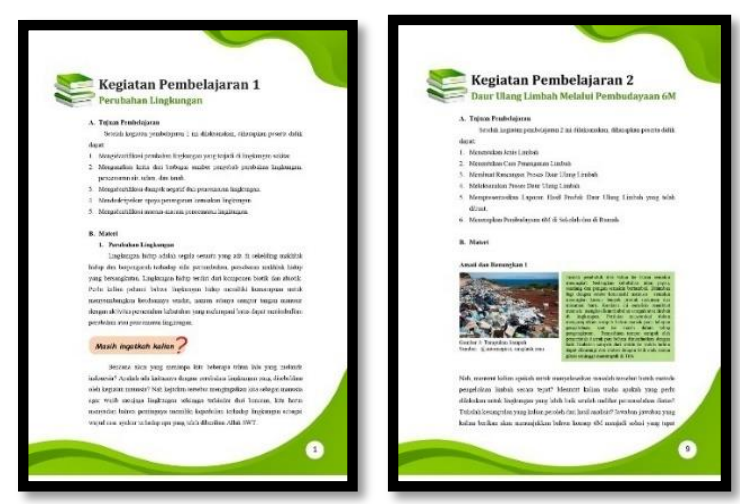

Gambar 7. Kegiatan Pembelajaran 1 dan Kegiatan Pembelajaran 2
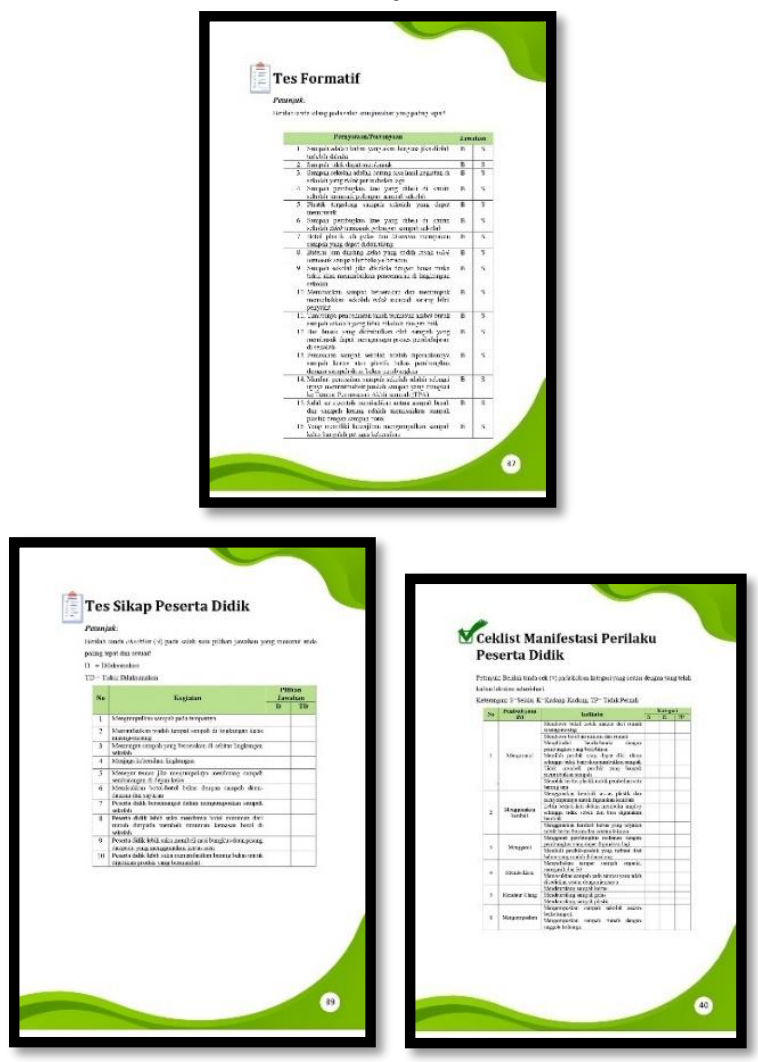

Gambar 8. Tes formatif, Tes Sikap, dan Checklist Manifestasi Perilaku

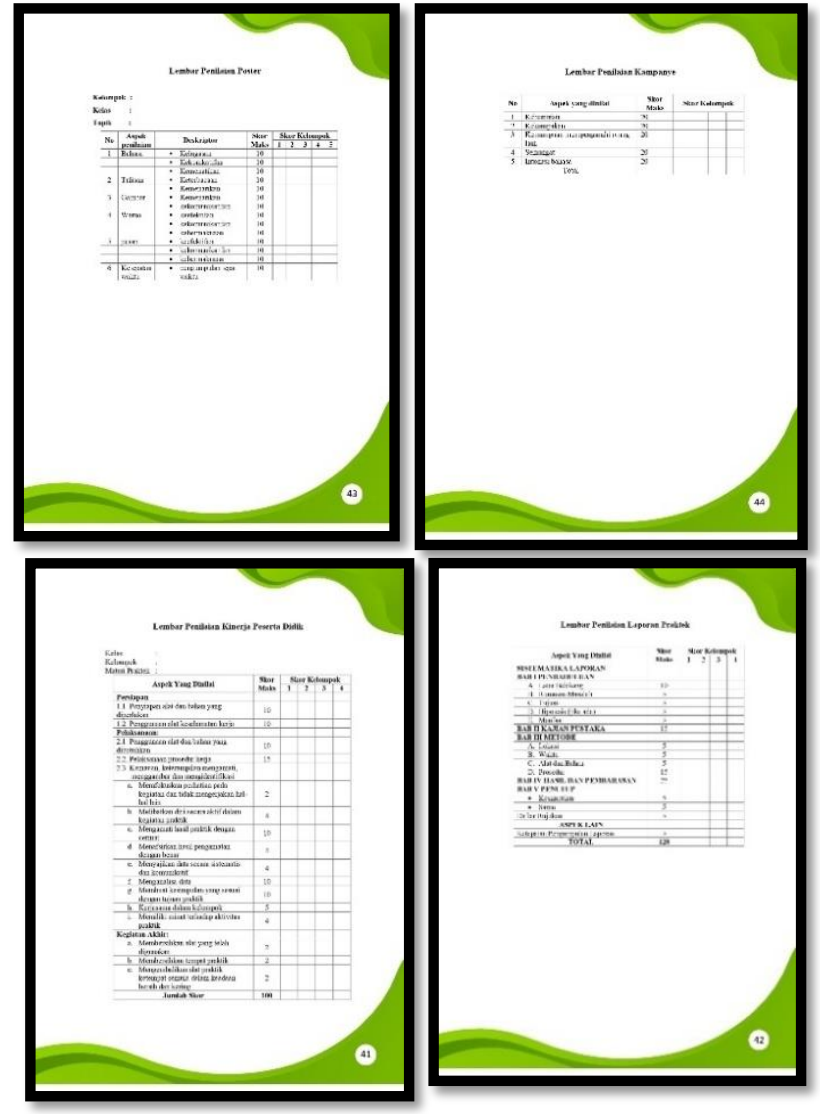

Gambar 9. Lampiran Lembar Penilaian

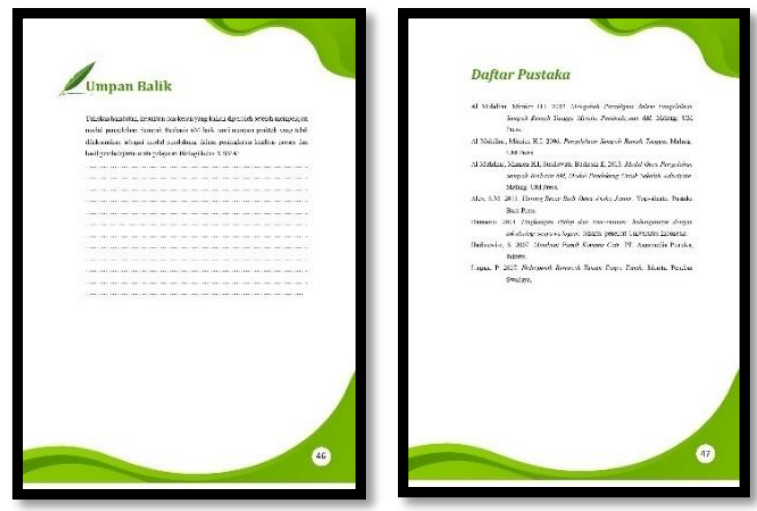

Gambar 10. Umpan Balik dan Daftar Pustaka

Salah satu penelitian lain tentang pengembangan bahan ajar berupa modul $6 \mathrm{M}$ berbasis project based learning diantaranya telah dilakukan sebelumnya oleh Vendiktama, (2019) ${ }^{[5]}$ yang menunjukkan bahwa karakteristik modul biologi yang dikembangkan diintegrasikan dengan sintak project based learning memudahkan siswa memperoleh pengalaman belajar dan terlibat secara aktif dalam pelaksanaan tugas proyek sehingga menghasilkan karya atau produk. Saran yang ditekankan pada penelitian ini adalah agar modul yang dikembangkan 
dijadikan sebagai bahan rujukan untuk mengembangkan bahan ajar baik itu oleh guru yang penekanannya lebih kepada aspek keterampilan, serta harus dilakukan validasi oleh pihak yang kompeten agar dapat menghasilkan produk modul yang lebih baik.

\section{KESIMPULAN}

Kesimpulan penelitian berdasarkan hasil penelitian dan pembahasan adalah bahwa Modul 6M berbasis project based learning untuk peserta didik SMA dinyatakan "sangat valid" dengan nilai rerata skor 3,5 dan persentase sebesar $\mathbf{8 7 , 5 \%}$ dan kriteria "Sangat Baik" dan keterangan "Tidak Perlu Direvisi".

\section{SARAN}

Saran untuk penelitian selanjutnya adalah (1) Modul 6M berbasis project based learning dapat digunakan sebagai referensi untuk mengembangkan materi dan metode pembelajaran yang sesuai dengan kebutuhan peserta didik. (2) Melakukan evaluasi ulang terkait hasil penerapan Modul 6M berbasis project based learning pada skala luas (seluruh SMA) agar nantinya dapat menghasilkan Modul yang lebih valid dari sebelumnya, (3) Memperkenalkan produk Modul 6M berbasis project based learning melalui forum ilmiah seperti pada workshop, seminar lokal/nasional/internasional, dan MGMP guru sekolah yang ada di Kabupaten Sumbawa Barat.

\section{UCAPAN TERIMA KASIH}

Artikel yang telah disusun ini merupakan bagian dari Penelitian Dosen Pemula (PDP) dengan judul "Pengembangan Modul 6M berbasis project based learning untuk Meningkatkan Hasil Belajar Peserta Didik SMA di Kabupaten Sumbawa Barat". Penelitian telah dibiayai oleh Direktorat Riset dan Pengabdian Masyarakat, Deputi Bidang Penguatan Riset dan Pengembangan, Kementerian Riset dan Teknologi/Badan Riset dan Inovasi Nasional sesuai dengan Kontrak Penelitian Tahun Anggaran 2021. Ucapan terimakasih kami sampaikan kepada semua pihak yang telah membantu terutama kepada Kementerian Riset dan Teknologi/Badan Riset dan Inovasi Nasional, Program Studi Pendidikan Biologi, Fakultas Keguruan dan Ilmu Pendidikan (FKIP) Universitas Cordova, LRP2M Universitas Cordova, Bappeda Litbang Kabupaten Sumbawa Barat, SMA Negeri 1 Brang Rea, rekan tim, serta semua pihak-pihak yang terlibat dalam penelitian ini. Semoga ini menjadi amal jariyah kita dan bermanfaat untuk semua pihak.

\section{DAFTAR PUSTAKA}

[1] Saprin. 2016. Optimalisasi perang guru dalam peningkatan kegiatan belajar peserta didik di MTS Madani Alauddin Paopao Kabupaten Gowa. Jurnal inspiratif pendidikan Vol.5 No 2. E-ISSN 2655-4445.

[2] Kosasih. 2014. Strategi belajar dan pembelajaran. Bandung: Yarma Widya.

[3] Mahanal, S. 2009. Pengaruh Penerapan Perangkat Pembelajaran Deteksi Kualitas Sungai dengan Indikator Biologis Berbasis Proyek terhadap Hasil Belajar Siswa SMA di Kota Malang. Disertasi tidak diterbitkan. Malang: Program Pascasarjana Universitas Negeri Malang

[4] Sumi Branch, R.M. (2009). Instructional Design: The ADDIE Approach. Speingger Science Business Media, LLC.ati, dan Asra. 2009. Metode Pembelajaran. Bandung: Wancana Prima.

[5] Vendiktama, P.R., Al-Muhdar, M.H.I. dan Suarsini, E. 2018. Pengembangan Modul BiologiBermuatanKonsep 6M dan Etika LingkunganBerbasis Model Project Based Learning (PjBL) untukSiswa SMA.Jurnal Pendidikan. Volume 3 (2). Februari 2018. 
E-ISSN: 2502-471X. DOAJSHERPA/RoMEO-Google

Scholar-IPI.

[6] Fajarianingtyas, D.A., dan Hidayat, J.N. 2019.Validitas Buku Petunjuk Praktikum Biologi Dasar Berbasis Pemecahan Masalah untuk Mahasiswa Pendidikan IPA di Universitas Wiraraja. Lensa (LenteraSains): Jurnal Pendidikan IPA. Volume 9 (2). November 2019. ISSN: 23015071. e-ISSN: 2406-7393.

[7] Sahratullah dan Rahmawati, F. 2020. Pengembangan petunjuk praktikum berbasis guided inquiry untuk peserta didik SMA di Kabupaten Sumbawa Barat. Jurnal Ilmiah Mandala Education (JIME), 6 (2), 474481 